\title{
LOBSTER AIR TAWAR (Parastacidae: Cherax), ASPEK BIOLOGI, HABITAT, PENYEBARAN, DAN POTENSI PENGEMBANGANNYA
}

\author{
Titin Kurniasih*) \\ *) Balai Riset Perikanan Budidaya Air Tawar, Bogor
}

\begin{abstract}
ABSTRAK
Lobster air tawar (genus Cherax) berasal dari Australia, Papua New Guinea, dan Irian Jaya, dengan spesies yang berbeda-beda. Salah satu spesiesnya yang bernilai ekonomis paling tinggi adalah Cherax quadricarinatus (red claw ). Habitat Cherax adalah perairan tawar yang dangkal, dengan substrat berlumpur dan banyak terdapat celah serta rongga untuk menyembunyikan diri. Kelebihan terbaiknya adalah teknik budidayanya yang relatif mudah, toleransi terhadap lingkungan cukup tinggi dengan masalah penyakit yang relatif sedikit. Hanya disayangkan hingga saat ini perkembangan kegiatan budidaya Cherax masih sangat terbatas.

\section{KATA KUNCl: lobster air tawar, redclaw, toleran, budidaya terbatas}

\section{PENDAHULUAN}

Lobster air tawar (Cherax) sudah dikenal masyarakat dunia, terutama Australia sejak tahun 1975. Australia telah membudidayakan dan mengekspor Cherax ke berbagai negara dalam 20 tahun terakhir. Namun di Indonesia, keberadaan Cherax ini masih tergolong langka, baik kegiatan budidaya maupun aktivitas konsumsinya.

Tulisan ini mengupas aspek biologi, penyebaran, habitat ekologis, potensi dan perkembangan budidaya Cherax di dunia, serta status dan peluang budidaya Cherax di Indonesia saat ini. Diharapkan informasi ini dapat menggugah kita untuk terus memanfaatkan sekaligus mengembangkan kekayaan plasma nutfah Indonesia untuk kesejahteraan masyarakat.

\section{ASPEK BIOLOGI DAN MORFOLOGI}

Menurut Holthuis (1949) dan Riek (1968), Cherax diklasifikasikan sebagai berikut:

$\begin{array}{ll}\text { Phylum } & \text { : Arthropoda } \\ \text { Klas } & \text { : Crustacea } \\ \text { Ordo } & \text { : Decapoda } \\ \text { Family } & \text { : Parastacidae }\end{array}$

Genus : Cherax

Species : Cherax quadricarinatus/ red claw, Cherax destructor/ yabbie Cherax tenuimanus/ marron

Menurut Lowery (1988), genus Cherax merupakan udang air tawar yang mempunyai bentuk seperti lobster karena memiliki capit yang besar dan kokoh, serta rostrum picak berbentuk segitiga yang meruncing. $\mathrm{Di}$ Indonesia, jenis udang ini belum banyak dikenal masyarakat karena menurut Sabar (1975), genus Cherax masih hidup liar di sungai-sungai di Irian Jaya.

Martosudarmo \& Ranoemihardjo (1980) mengemukakan bahwa tubuh udang secara morfologi dapat dibagi menjadi dua bagian, yaitu sefalothoraks (bagian kepala dan dada) dan bagian abdomen (perut/badan), demikian juga tubuh Cherax. Layaknya krustasea yang lain, Cherax memiliki kerangka luar dan tidak memiliki kerangka dalam. Sefalotoraks terdiri atas sepasang antena, sepasang antenulla, sepasang maksila, mandibula, maksilipedia dan 4 pasang kaki jalan (pereipoda) sedangkan abdomen terdiri atas 6 pasang kaki renang (pleopoda), 2 pasang ekor samping (uropoda) dan satu buah telson. Penutup sefalothoraks tersusun dari zat tanduk atau kitin yang tebal dan disebut karapas. Zat tanduk ini merupakan nitrogen polisakarida $\left(\mathrm{C}_{8} \mathrm{H}_{13} \mathrm{O}_{5} \mathrm{~N}\right)_{x}$ yang disekresikan oleh epidermis dan dapat mengelupas (moulted) pada interval waktu tertentu. Fungsi karapas adalah untuk melindungi organ-organ bagian dalam seperti insang, alat pencernaan termasuk organ hepatopankreas, jantung dan organ reproduksi.

Selanjutnya Martosudarmo \& Ranoemihardjo (1980) menerangkan bahwa tubuh Cherax terdiri atas segmensegmen atau ruas-ruas, namun segmentasi ini tidak terlihat dari luar karena tertutup oleh karapas. Masingmasing segmen memiliki anggota badan dengan fungsi bermacam-macam. Anggota badan tersebut mulai dari ruas badan terdepan hingga ruas badan terakhir terdiri atas: tangkai mata, antenulla, antena, mandibula, maksila, maksiliped, periopoda, pleopoda, dan uropoda. Secara garis besar struktur tubuh Cherax tidak terlalu berbeda dengan struktur tubuh udang jenis lainnya. Gambar 1 menyajikan struktur morfologi Cherax. 


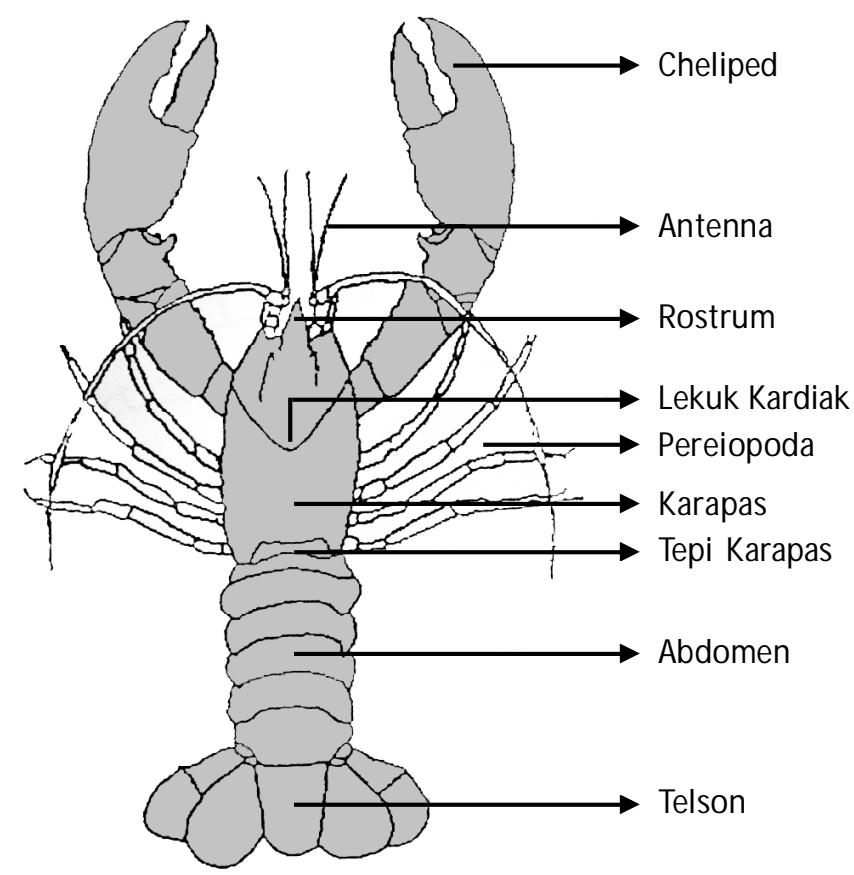

Gambar 1. Struktur morfologi Cherax (BPPT-LBN LIPI, 1983/1984)

Menurut Johnson (1978), sebagian besar organ dalam udang terdapat pada bagian sefalotoraks. Sedangkan otot sebagian besar berada pada bagian abdomen, dan usus memanjang dari sefalotoraks sampai ke ujung abdomen. Struktur anatomi Cherax disajikan dalam Gambar 2.

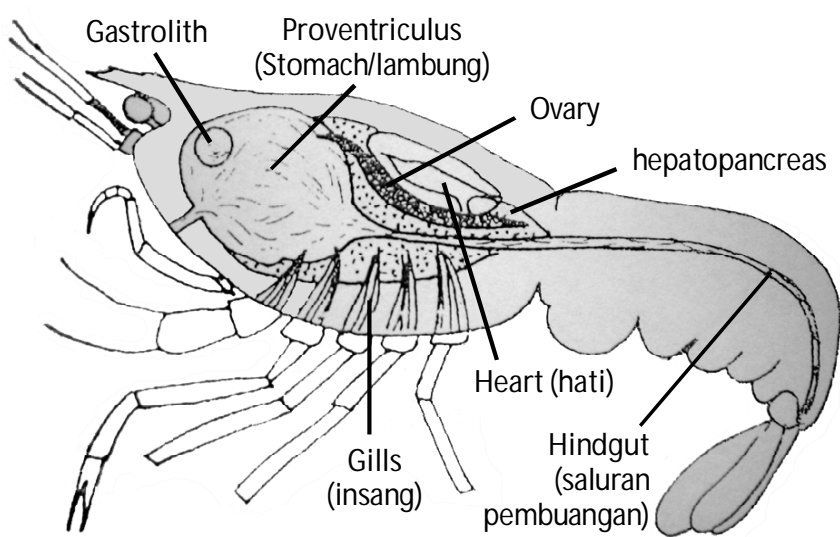

Gambar 2. Struktur Anatomi Cherax (Curtis \& Jones, 1995)

\section{HABITAT DAN PENYEBARAN}

Francois (1960) mengemukakan bahwa jenis lobster air tawar terdiri atas famili Astacidae yang terdapat di belahan bumi utara, dan famili Parastacidae di belahan bumi bagian selatan. Riek (1968) menyatakan bahwa famili Parastacidaeyang terdiri atas 14 genus tersebar di belahan bumi selatan, yaitu Madagaskar, Tasmania, Australia,
Selandia Baru, Irian, dan Amerika Selatan. Salah satu genus yang cukup terkenal adalah genus Cherax (Francois, 1960).

Holthuis (1949) melaporkan bahwa genus Cherax banyak terdapat di daerah Australia, Irian dan pulau-pulau di sekitarnya. Hingga kini telah diketahui bahwa di Irian Jaya terdapat 12 spesies, di Papua New Guinea ada dua spesies (Sabar, 1975) sedangkan di Australia ada 27 spesies (Riek, 1968). Di Irian Jaya, menurut Sabar (1975), setiap spesies Cherax memiliki nama lokal yang berbeda-beda, antara lain Udi, Obawo, Dede, Murido, Talia, Bopa, dan Juri.

Menurut Salmon \& Hyatt (1983) teritorialitas atau sistem daerah teritorial merupakan ciri utama pada hewan krustasea, terutama ordo Decapoda, karena pada umumnya jenis hewan ini sangat suka berkelahi. Namun Masser \& Rouse (1997) berpendapat sebaliknya bahwa Cherax jenis red claw relatif suka berkelompok dan toleran terhadap kondisi yang padat, meskipun pada umur muda sering menunjukkan sifat agresif yang tinggi dengan perilaku kanibalisme.

Odum (1994) mendefinisikan habitat atau tempat tinggal adalah suatu ruang tertentu sebagai tempat suatu organisme, yang terdiri atas faktor-faktor fisika, kimia, dan biologi. Habitat Cherax adalah aliran air yang dangkal dan perairan tawar (Storer \& Usinger, 1961), misalnya danau, rawa dan sungai. Frost (1975) melaporkan bahwa Cherax di Australia hidup pada kedalaman 0,8--1,0 meter. Kedalaman kurang dari 0,8 meter menyebabkan kematian karena perubahan suhu selama musim panas. Menurut Rouse (1977), habitat alami Cherax jenis red claw adalah wilayah tropis Australia bagian utara yaitu daerah Queensland. Genus Cherax yang ada di Danau Paniai, Irian Jaya hidup di dasar perairan dan kadangkadang membenamkan diri di lumpur (Anonim, 1977). Menurut Holthuis (1949), Cherax dapat hidup di daerah dataran rendah maupun dataran tinggi. M ereka cenderung bersembunyi di celah dan rongga bebatuan, potongan pohon dan di antara akar tanaman rawa (Iskandar, 2003).

Rouse (1977) mengemukakan, dari banyak spesies Cherax yang ada di Australia, ada tiga spesies yang saat ini sedang digalakkan pembudidayaannya, yaitu Cherax tenuimanus (marron), Cherax destructor (yabbie) dan Cherax quadricarinatus (red claw). Ketiga spesies ini berasal dari wilayah Australia yang berbeda dengan penyebaran alamiah yang berbeda pula. Gambar 3 menampilkan peta distribusi dari tiga spesies Cherax di Benua Australia.

Sebelum tahun 1975, hanya sedikit sekali yang mengetahui mengenai reproduksi Cherax ini. Setelah 
Cherax quadricarinatus

(red claw)

Cherax destructor

(yabbie)

Cherax tenuimanus

(marron)

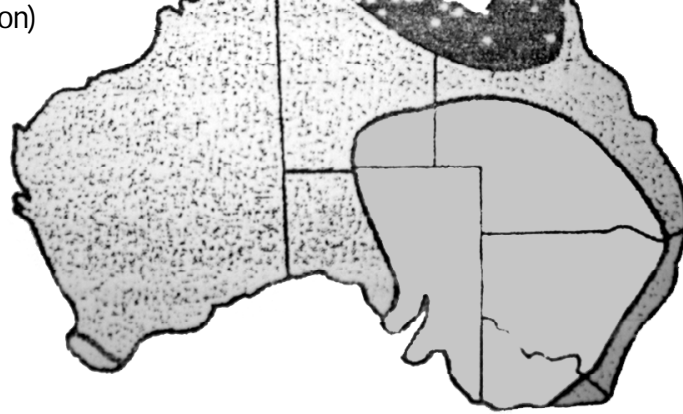

Gambar 3. Distribusi genus Cherax di benua Australia (Masser \& Rouse, 1997)

produksi Cherax mendapatkan status legal di Australia banyak ahli akuakultur yang antusias untuk meneliti potensi jenis udang liar ini untuk dibudidayakan. Genus Cherax ini kemudian banyak dipelajari dari berbagai aspek, bahkan Australia telah mengekspornya sejak 20 tahun terakhir dengan label perdagangan 'spiny lobster' dan harganya cukup baik. Tanpa disadari, penyebaran genus Cherax asal Australia ini kini meluas ke seluruh negara, dan permintaan pasar akan jenis udang ini sangatlah tinggi.

Bardach et al. (1972) menyatakan bahwa pertumbuhan optimum Cherax adalah pada kisaran suhu $21^{\circ} \mathrm{C}-29^{\circ} \mathrm{C}$. Suhu yang terlalu rendah atau terlalu tinggi akan mengganggu pertumbuhan dengan kecenderungan membenamkan diri dalam lumpur atau menjadi tidak aktif.

Kondisi kualitas air optimal untuk Cherax jenis red claw meliputi: oksigen $>1 \mathrm{mg} / \mathrm{L}$, kesadahan dan alkalinitas $20--300 \mathrm{mg} / \mathrm{L}$, dan pH 6,5--9,0. Jenis red claw dewasa menunjukkan toleransi terhadap kadar oksigen terlarut sampai $1 \mathrm{mg} / \mathrm{L}$, tetapi red claw muda lebih rentan. Red claw juga toleran terhadap konsentrasi amonia terionisasi sampai $1,0 \mathrm{mg} / \mathrm{L}$ dan nitrit sampai $0,5 \mathrm{mg} / \mathrm{L}$ dalam jangka waktu yang pendek (Rouse, 1977).

Frost (1975) berpendapat, genus Cherax merupakan pemakan oportunis, terutama sisa-sisa tumbuhan (serasah) dan koloni mikroba yang banyak ditemukan pada dasar kolam. Menurut Iskandar (2003), lobster air tawar adalah pemakan segala (omnivora), tetapi menurut Goddard (1988), termasuk hewan herbivora dan karnivora. Cherax sebagai herbivora memakan tanaman air, wortel, kentang, bayam, pisang dan tomat; sedangkan sebagai karnivora memakan moluska, larva serangga, cacing, krustasea kecil, amfibi, dan pemakan jenis sendiri (kanibalisme). Sedangkan Rouse (1977) melaporkan bahwa makanan alami yang cocok untuk Cherax adalah jenis makanan seperti wortel, seledri dan hati.

Meskipun Cherax dapat tetap bertahan hidup dan tumbuh tanpa makanan tambahan (Kondos, 1990; LoyaJavellana et al., 1993), tetapi tingkat pertumbuhan terbaik hanya dapat dicapai bila pasokan makanan cukup. Beberapa studi menunjukkan bahwa penggunaan pelet komersial dapat memberikan hasil yang memuaskan. Tingkat pertumbuhan benih yang bagus dapat juga dicapai jika zooplankton berkembang dengan baik di kolam.

Lobster air tawar aktif mencari makan pada malam hari (nokturnal). Pada kolam pembudidayaan, Jones $\&$ Ruscoe (2001) menyarankan penggunaan bahan-bahan tertentu seperti pipa PVC, batu koral, batu bata atau mesh sebagai tempat persembunyian, karena sifatnya yang suka menggali untuk bersembunyi.

\section{POTENSI DAN PENGEMBANGAN}

Menurut Rouse (1977) dan Curtis \& Jones (1995), Cherax quadricarinatus (red claw) memiliki nilai ekonomis paling tinggi dibandingkan jenis lobster air tawar lainnya yang telah dibudidayakan di Australia, seperti marron (Cherax tenuimanus) dan yabbie (Cherax destructor). Kelebihan red claw ini antara lain adalah kecepatan tumbuhnya yang jauh lebih besar dibandingkan jenis Cherax lain (dapat mencapai ukuran panjang $30 \mathrm{~cm}$ dan bobot 500--600 gram), produktivitas per are dan pertahunnya lebih besar, proporsi daging lebih banyak, rasa dagingnya lebih enak, toleransi lingkungan lebih tinggi, masalah penyakit relatif sedikit, mudah dijual hidup dan dikapalkan ke seluruh dunia, dan pasar terbuka lebar (Jones et al., 2000).

Permintaan Cherax untuk keperluan konsumsi adalah dari Jepang, Malaysia, Hongkong, Cina, Taiwan, Korea, dan Singapura. Selain itu, Amerika Serikat, Kanada, Perancis, Belanda, Jerman, Belgia, Selandia Baru, dan Australia menjadikan lobster air tawar sebagai makanan favorit karena keyakinan lebih menyehatkan daripada makanan laut.

Cherax memiliki ukuran tubuh yang lebih besar sehingga kandungan dagingnya lebih banyak. Tekstur dagingnya lebih kenyal dan rasanya lebih gurih daripada lobster air laut. Kandungan lemak, kolesterol, dan garamnya lebih rendah sehingga aman dikonsumsi oleh semua konsumen (Wiyanto \& Hartono, 2003). Selain itu, tidak sedikit orang yang percaya bahwa daging lobster air tawar dapat meningkatkan vitalitas dan gairah seksual kaum wanita. Kandungan seng yang cukup tinggi dapat memacu produksi libido dan meningkatkan aktivitas sperma kaum pria (Iskandar, 2003). 
Dengan segala kelebihannya ini, tidaklah mengherankan apabila red claw memasuki pangsa pasar dunia, dengan harga jual yang cukup menjanjikan. Tabel 1 menyajikan harga jual red claw di pasar dunia.

Tabel 1. Harga jual Cherax quadricarinatus (red claw) di pasar dunia (Molony et al., 2002)

\begin{tabular}{lc}
\hline \multicolumn{1}{c}{ Ukuran } & Harga/ekor (US\$) \\
\hline Benih 0,3--0,5 oz (8,5--14,2 g) & 0,35 \\
Dewasa muda 0,5--0,8 oz (14,2--22,7 g) & 0,68 \\
Calon induk 0,8--1,7 oz (22,7-48,2 g) & 1,36 \\
Induk (jumbo) 1,72--2,8 oz (48,8--79,4 g) & 3,02 \\
Lobster lebih dari 2,8 oz (79,4 g) & 6,05 \\
\hline
\end{tabular}

Wiyanto \& Hartono (2003) menyebutkan bahwa harga lobster air tawar konsumsi di kota-kota besar di Indonesia adalah Rp 200.000,--- Rp 300.000,- per kg, dengan ukuran 9--12 ekor per kg. Tabel 2 menyajikan harga Cherax di kota Bogor, pada tahun 2007.

Tabel 2. Harga jual Cherax quadricarinatus (red claw) di Tofano Fishery Bogor tahun 2007

\begin{tabular}{ccc}
\hline $\begin{array}{c}\text { Ukuran lobster } \\
\text { (inci) }\end{array}$ & $\begin{array}{c}\text { Umur } \\
\text { (bulan) }\end{array}$ & $\begin{array}{c}\text { Harga/ekor } \\
\text { (Rp) }\end{array}$ \\
\hline 1 & 2 & 2,500 \\
1,5 & 2,5 & 3,000 \\
2 & 3 & 4,000 \\
3 & 4 & 6,000 \\
\hline
\end{tabular}

Dengan melihat data di atas, maka red claw dapat dijadikan salah satu komoditas budidaya yang prospektif mengingat negara Indonesia memiliki potensi lahan perairan yang cukup luas dan faktor lingkungan yang cukup baik.

Jika dibandingkan dengan udang lainnya seperti udang windu atau udang galah, Cherax lebih mudah dibudidayakan. Teknik budidayanya relatif sederhana dan tidak memerlukan lahan yang luas, karakternya tidak mudah stres dan tidak mudah terserang penyakit. Asalkan kebutuhan pakan, oksigen, dan kualitas air terpenuhi maka Cherax dapat tumbuh dan berkembang biak dengan cepat.

Jika dilihat dari kondisi lingkungan alam, Indonesia memiliki potensi yang sangat besar untuk pengembangan budidaya Cherax. Iklim dan siklus musim memungkinkan lobster dapat dibudidayakan sepanjang tahun. Red claw dapat bertelur 4--5 kali setahun, sementara di Queensland, Australia yang merupakan habitat aslinya, red claw hanya mampu bertelur dua kali setahun (Wiyanto \& Hartono, 2003). Selain itu, sumber pakan alami yang tersedia di alam cukup banyak dan mudah diperoleh, sehingga Cherax akan tumbuh lebih cepat.

\section{PERKEMBANGAN BUDIDAYA CHERAX DI INDO- NESIA}

Sejauh ini red claw maupun lobster air tawar lainnya hanya disajikan di restoran-restoran berkelas. Minimnya aktivitas budidaya Cherax dan meningkatnya permintaan pasar terhadap komoditas ini berdampak langsung terhadap meningkatnya aktivitas penangkapan/perburuan terhadap Cherax di alam. Apabila aktivitas penangkapan ini dilakukan secara terus-menerus tanpa batasan yang jelas dan tanpa pertimbangan akan kelestariannya, maka dikhawatirkan suatu saat keberadaan Cherax di Indonesia (yang hanya terdapat di Kabupaten Jayawijaya) terancam punah. Kondisi ini semakin memprihatinkan karena di Indonesia, Cherax ternyata baru dipelajari pada taraf permulaan dan berdasarkan koleksi yang sangat sedikit.

Beberapa tahun yang lalu, Pemerintah Daerah Papua telah berupaya mengembangkan potensi sumber daya genus Cherax, antara lain Cherax monticola dan Cherax lorentzi (Dinas Perikanan dan Kelautan Pemerintah Provinsi Papua, 2003). Hal yang telah dilakukan antara lain mempelajari aspek ekologi, domestikasi dan percobaan budidayanya. Hal serupa juga telah dilakukan oleh Balai Budidaya Air Tawar Sukabumi dan Balai Riset Perikanan Budidaya Air Tawar Bogor untuk Cherax quadricarinatus dan Cherax albertisii.

Hingga saat ini, budidaya lobster baru dilakukan terbatas di beberapa kota, seperti Jakarta, Yogyakarta, Surabaya, Bogor, Sukabumi, dan Bali. Karena itu, anggota famili krustasea ini memiliki peluang untuk dibudidayakan sebagai salah satu komoditas perikanan andalan.

\section{PENUTUP}

Berdasarkan uraian mengenai habitat, potensi, kelebihan serta kesesuaian alam Indonesia dan tersedianya lahan yang luas untuk pembudidayaan Cherax, sangatlah disayangkan apabila usaha budidaya lobster air tawar ini belum mendapat perhatian serius. Cherax dapat diandalkan sebagai pengganti budidaya udang payau yang telah menurun saat ini, bahkan dengan risiko yang jauh lebih rendah, namun keuntungan lebih besar. Perhatian Pemerintah dan instansi terkait sangat diperlukan dalam hal sosialisasi teknologi budidaya, penyediaan induk dan benih berkualitas, pembentukan forum pembudidaya lobster sampai dengan kemudahan akses pembiayaan usaha kecil. 


\section{DAFTAR PUSTAKA}

Anonim. 1977. Freshwater Crayfish of Yabbie Research. Fisheries Research Annual Report. 1975. Port Moresby. p. $21-22$.

Bardach, J.E., J.H. Rhyter, and W.O. McLarvey. 1972. Aquaculture, the Farming and Husbandry of Freshwater and Marine Organism. Willey Interscience. $651 \mathrm{pp}$.

BPPT-LBN LIPI. 1983/1984. Pengkajian Ekologi Udi, Cherax monticola sebagai Dasar Teknik Budidaya (Progress Report). BPPT-LBN LIPI. 112 pp.

Curtis, M.C. and Jones C.M. 1995. Overview of redclaw crayfish, Cherax quadricarinatus, farming practices in northern Australia. Freshwater Crayfish. 10: 447- 455.

Dinas Perikanan dan Kelautan Pemerintah Provinsi Papua. 2003. Inventarisasi Potensi Pengembangan Udang Cherax spp. Di Kabupaten Jayawijaya (Laporan Akhir). PT Parama Iruf Consultan Papua. 59 pp.

Francois, D.I. 1960. Freshwater Crayfish. Aust. Mus. Mag. 13 (7): 217-220.

Frost, J.V. 1975. Australian Crayfish. Paper from The Second International Symposium on Freshwater Crayfish. Lousiana State University, Baton Rouge, Lousiana. p. 87-96.

Goddard, J.S. 1988. Food and Feeding. In : Holdich, D.M. and R.S. Lowery (Editor). Freshwater Crayfish: Biology, Management and Exploitation. Croom Helm, London. p. 145- 166.

Holthuis, L.B. 1949. Decapoda Macrura with Revision of the New Guinea Parastacidae. Zoological Results of the Dutch New Guinea Expedition. Nova Guinea. New Ser. 5: 289-328.

Iskandar. 2003. Budidaya Lobster Air Tawar. Penebar Swadaya. Jakarta. 76 pp.

Johnson, S.K. 1978. Handbook of Shrimp Diseases. Texas $A$ and M University Sea Grant College, Texas Agriculturel Extension Services. USA. 23 pp.

Jones, C.M. and I.M. Ruscoe 2001. Assesment of five shelter in the production of redclaw crayfish Cherax quadricarinatus (Decapoda:Parastacidae) under earthen pond conditions. Journal of the World Aquaculture Society. 32: 41- 52.

Jones, C.M., C.P. McPhee, and I.M. Ruscoe. 2000. A review of genetic improvement in growth rate in redclaw crayfish Cherax quadricarinatus (Decapoda:Parastacidae). Aquaculture Research. 31: 6167.

Kondos, A. 1990. Supplementary feed essential for crayfish. Australian Fisheries. 49: 28- 30.

Loya-Javellana, G.N., D.R. Fielder, and M.J. Thorne. 1993. Food choice by free living stages of the tropical crayfish (Parastacidae : Decapoda). Aquaculture. 118: 299-308.

Lowery, R.S. Growth, moulting and reproduction. 1988. In : Holdich, D.M. and R.S. Lowery (Eds). Freshwater Crayfish: Biology, Management and Exploitation. Croom Helms, London and Sydney and Timber Press, Portland Oregon. p. 83- 113.

Martosudarmo, B. dan B.S. Ranoemihardjo. 1980. Biologi Udang Penaeid. In Pedoman Pembenihan Udang Penaeid. Ditjen Perikanan Jakarta. p. 1-21.

Masser, M.P. and D.B. Rouse. 1997. Australian Redclaw Crayfish. Southern Regional Aquaculture Center. $244 \mathrm{pp}$.

Molony, B., N.M. Morrissy, and C. Bird. 2002. The West Australian recreational marron fishery (Cherax tenuimanus Smith): history and future challenges. Freshwater Crayfish. 13: 207-220.

Odum, E.P. 1994. Dasar-dasar Ekologi (terjemahan). Universitas Gajah Mada. Yogyakarta. 317 pp.

Riek, E.F. 1968. The Australian Freshwater Crayfish (Crustacea: Decapoda: Parastacidae), with Description of New Species. Australian Journal Zoology. 17(3): 855918.

Rouse, D.B. 1977. Production of Australian Red Claw Crayfish. Auburn University. Alabama. USA. 11 pp.

Sabar, F. 1975. Udi (Crayfish) di Irian. Buletin Kebun Raya. 2(1): 27-29.

Salmon, M. and G.W. Hyatt. 1983. Communication p. 140. In D.E. Bliss (Ed.) The Biology of Crustacea. Vol II: Behaviour and Ecology. Academic Press. New York. p. $179-270$.

Storer, T.I. and Usinger. 1961.Element of Zoology. Second Edition. McGraw-Hill Books Company Inc. 463 pp.

Wiyanto, H. dan R. Hartono. 2003. Lobster Air Tawar, Pembenihan dan Pembesaran. Penebar Swadaya. Jakarta. 79 pp. 